\title{
Pendekatan Pembangunan Terpusat pada Penanggulangan Kemiskinan (Analisis Pendekatan Model Adelman)
}

\author{
Oleh : Syafaruddin Alwi
}

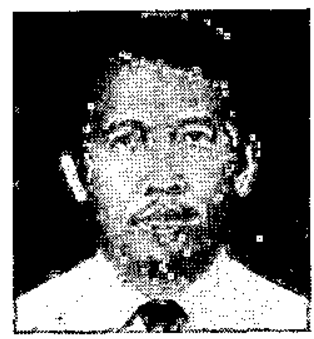

Syafaruddin Alwi, lahir di Baturaja pada tanggal 16 Januari 1947, adalah Lektor pada Fakultas Ekonomi UII. Pernah menjabat sebagai Dekan pada Fakuitas tersebut selama tiga periode yaitu tahun 1982-1988. Pada tahun 1973 s/d 1978 menjadi Ketua LPPM pada Fakultas yang sama sehingga sering melakukan kerja sama dalam pembinaan koperasi dengan berbagai Instansi baik swasta maupun pemerintah. Pada tahun 1986 mengikuti program Fellwship pada Australia National University di Canbera. Aktif mengikuti Seminar baik nasional maupun Internasional.

\section{Pengantar}

Adelman (1987), dalam tulisannya tentang struktur kemiskinan di negaranegara berkembang menjelaskan bahwa bagian terbesar dari kaum termiskin $40 \%$ dari penduduknya terlibat dalam kegiatankegiatan pertanian. Mereka yang hampir tidak memiliki tanah adalah yang paling miskindari kaum pekerja-pekerjayang tidak terlatih di sektor jasa-jasa, tetapi mereka pun , pada umumnya lebih kaya dibandingkan dengan kaum miskin pedesaan. Parapekerjadisektormanufaktur, apakah mereka itu terlatih atau tidak, merupakan bagian 20-40\% penduduk yang paling kaya. Jadi tenaga kerja tidak terlatih merupakan milik utama kaum miskin dan yang menentukan arah kemiskinan adalah adanya permintaan akan produktivitas dari tenaga kerja mereka itu.

Ulasan ini menariksekali untuk dikaji lebih jauh karena jika penggambaran tersebut mewakili karakteristik dari hainpir kebanyakan negara-negara berkembang termasuk Indonesia, maka yang diperlukan untuk mengatasi keadaan itu, tịndakantindakan konkrit yang dapat membantu kaum miskin melepaskan ketergantungannya kepada faktor penentu permintaan produktivitas itu. Faktor-faktor penentu yang dimaksud dapat berupa sejauhmana kekuatan pasar bagi produk mereka, bagaimana keadilan dalam pendistribusian bantuan modal dan 
pengembangan saranayang bisamendorong dinamika kehidupan ekonomi mereka dsb.

Bantuan-bantuan apa yang dapat diberikan dalam upaya meningkatkan kemampuan ekonomi masyarakat yang tergolong miskin, dipengaruhi oleh pilihanpilihan pendekatan apa yang dijalankan dalam pembangunan. Pendekatan apa yang dipakai akan menentukan strategi apa yang . dilaksanakan dalam mempercepat proses pengentasan kemiskinan. Penanggulangan kemiskinan merupakan salah satu tujuan pembangunan dibidang ekonomi di setiap negera berkembang. Tetapi hasil-hasil pembangunan di negara berkembang pada umumnya, kurang menunjukkan tercapainya sasaran tersebut. Hal ini disebabkan kekeliruan dalam pemilihan strategi pembangunan pada tahap awal.

Indonesia tidak terkecuali. Diujung proses pembangunan ekonomi Pelita V, kita dikejutkan oleh pengumuman BAPPENAS bahwa di Indonesia masih banyak daerah yang mérupakan kantongkantong kemiskinan. Melalui survey 1993 (Mubyarto, 1994), diketahui terdapat 20.633 desa yang merupakan kantongkantong kemiskinan yang dikenal dengan istilah Desa Tertinggal. Dari jumlah tersebut 3.968 desa tergolong berada pada kondisi miskin parah. Dari jumlah yang tergolong paling parah kondisinya ini, 813 desa di Jawa dan Bali, sedangkan bagian terbesar sebanyak 3.155 desa terletak diluar Jawa dan Bali. Secara keseluruhan saat ini mäsih terdapatsebanyak 27,2 jutaorang penduduk yanghidup dibawah garis kemiskinan, yang memerlukan penanggulangan yang serius. Keseriusanini ditunjukkan oleh pemerintah dengan menyusun program Inpres Desa Tertinggal (IDT) yang mentargetkan sasaran pengurangan jumlạh penduduk miskin pada akhir Pelita VI menjadi tinggal 12 juta atau 5-6\% dari penduduk Indonesia secara keseluruhan.

Oleh sebab itu tulisan ini akan membahas tentang pendekatan pembangunan yang terpusat pada pengentasan kemiskinan, pilihan-pilihan strategi dan bantuan-bantuan yang diperlukan dalam kontek pendekatan dan strategi tersebut.

\section{Alternatif Pendekatan dan Strategi}

Pendekatan pembangunan yang berorientasi pada pertumbuhan tinggi dalam iklim stabilitas politik yang dijalankan oleh . Indonesia pada tahun 1970-an, ternyata kurang berhasil menyelesaikan masalah kemiskinan akibat tidak terjadinya pendistribusian yang meratạ atas hasil-hasil pembangunan dan dominasi peran pemerintah yang menyebabkan rendahnya partisipasi masyarakat dalam proses pembangunan ekonomi. Akibatnya tingkat pendapatan masyarakat yang tergolong miskin relatif tidak meningkat sehingga tingkat kesenjangan dengan masyarakat kaya tetap lebar. Kemerataan pendapatan dengan menggúnakan indeks Gini menunjukkan kesenjangan ini (tabel 2.1) walaupun jumlah penduduk miskin cenderung turun (tabel2.2). Kini pada akhir Pembangunan Jangka Panjang Kedua, masalah kemiskinan ini pun tetap merupakan isu pokok pembangunan ekonomi walaupun strategi pertumbuhan telah dikoreksi selama rangkaian pelita IIpelita $\mathrm{V}$ program pemerataan telah dijalankan. 
TABEL 2:1

Bagian Pendapatan Indonesia $10 \%$ Terbawah 1964-1990

\begin{tabular}{|c|c|c|c|c|c|c|c|c|}
\hline \multirow{2}{*}{$\begin{array}{c}\text { Tahun } \\
.\end{array}$} & \multirow{2}{*}{$\begin{array}{l}\cdots \\
\cdots\end{array}$} & \multicolumn{2}{|c|}{ Kota } & \multicolumn{2}{|c|}{ - Desa ' } & & \multicolumn{2}{|c|}{ Indonesia } \\
\hline & & Gini & $10 \mathrm{z}$. & Gini & $10 x^{2}$ & & Gini & 107 \\
\hline 1964 & & 0,34 & 3,1 & 0,35 & 2,9 & & ז 0,35 & 2,8 \\
\hline 1969 & $\therefore$ & 0,33 & 3,1 & 0,34 & $\mathbf{3}, \mathbf{0}$ & & 0,35 & $\mathbf{3}, \mathbf{0}$ \\
\hline 1976 & . & 0,35 & $\mathbf{3}, \mathbf{1}$ & 0,31 & 3,8 & & . 0,34 & 3,4 \\
\hline 1980 & & 0,36 & 3,6 & 0,31 & 3,6 & & 0,34 & 3,3 \\
\hline-1984 & & 0,32 & 3,3 & 0,28 & 3,9 & & $\dot{0}, 32$ & 3,4 \\
\hline 1987 & : & 0,32 & 3,6 & 0,26 & 4,4 & & 0,32 & 3,7 \\
\hline 1990 & & 0,34 & $\mathbf{3}, \mathbf{5}$ & 0,25 & 4,8 & & $\quad 0,32$ & $4: 0$ \\
\hline
\end{tabular}

Sunber: Seri Ștátistik Indonesia, BPS, Jakrerta.

TABEL 2.2

Perkembangan Penduduk, Miskin Kòta dam Desa

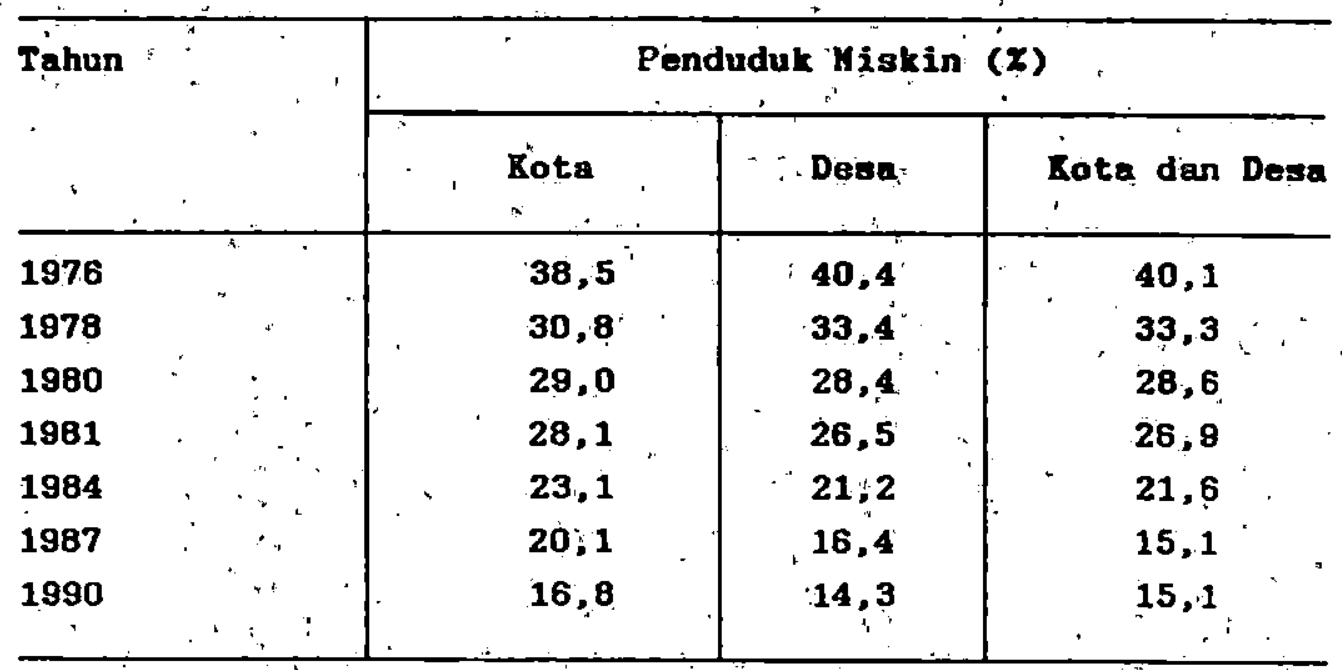

Sumber : .BPS, 1992.

Dari tabel 2.1 dapat dilihat bahwa pembangunan sejak tahun 1969-1990. tingkatkesenjangan secara nasional sédikit Penurunan hanya terlihat sécara sektoral sekali mengạami penurunan selama proses yaitu kotâ dạ desạa. Angka itumenunjukkan 
kesenjangan di desa mengalami perbaikan lebih cepat jika dibandingkan dengan kesenjangan yang terjadi di kota. Ada dugaan hal ini disebabkan tingkat urbanisasi yang meningkat dan transfer pendapatan dari kota ke desa.(Hasibuan, 1994).

Para pakarpadaumumnya mengakui bahwa tidak terdapat korelasi yang kuat antara pertumbuhan ekonomi dengan pendistribusian yang merata. Pendistribusian tidak bisa hanya diserahkan kepada mekanisme ekonomi tetapi juga menyangkut politik (kebijaksanaan). Ini berarti strategi pertumbuhan yang tidak disertai oleh upaya-upaya yang dapat mendorong dinamika kehidupan ekonomi kaum miskin, kurang bermakna dalam menyelesaikan kemiskinan itu sendiri. Oleh sebabitu diperlukan berbagai kebijaksanaan dan bantuan konkrit yang berorientasi kepada penanggulangan kemiskinan. Ini berarti dalam pergeseran struktural yang terjadi dalam perekonomian kita harus diantisipasi jangan sampai industrialisasi hanya didukung oleh kekuatan perekonomian modern dan bantuanbantuan baik dalam pengertian modal, teknis danmanajerial, dikembangkan hanya bagi kepentingan sektor modem tersebut.

Secara teoritik, pendistribusian itu akanmeratajikaproses pembangunan dapat menaikkan bagian pendapatan yang diterima kaum miskin (umumnya terlibat disektor primer atau tradisịnal) secara "proporsional" dengan kenaikan pendapatan masyarakat yang terlibat dalam kegiatan ekonomi disektor modem.

Ada tiga cara pendekatan terhadap strategi pembangunan yang terpusat pada kemiskinan yang ditawarkan oleh Alelman (1987) yang terdiri dari upaya mencapai salah satu atau lebih sasaran-sasaran berikut:
1. Pendekatan yang berorientasi pada peningkatan jumlah kekayaan yang dimiliki kaum miskin.

2. Pendekatan yang berorientasi pada peningkatan volume penjualan barangbarang mereka dipasaran.

3. Pendekatan yang. berorientasi meningkatkan harga jasa yang mereka jual.

Pendekatan yang pertama memang sangat ideal yaitu, mendorong kebijaksanaan untuk meredistribusikan kembali tanah dan bantuan untuk memperoleh pendidikan bagi kaum miskin agar siap menghadapi proses industrialisasi yang cepat. Hollis Chenery dkk (1974), sangat mendukung perlunya strategi seperti ini. Tanpamengurangi kebijaksanaan dalam pengaturan pemilikan tanah, bagi kita masalahpendidikan bagikaum miskin perlu lebih ditekankan untuk menghindarkan terjadinya proses urbanisasi prematur baik disektor sekunder maupun sektor tersier sebagai akibat sempitnya lahan pertanian disektor primer. Disamping itu meningkatnya pendidikan di kalangan pendudukmiskinterutama di pedesaan akan mendorong peningkatan produktivitas disektor primer.

Pendekatan yang kedua sangat relevan untuk dipertimbangkan karena strategi industrialisasi di Indonesia mengandalkan pendekatan keseimbangan antara sektor industri dan pertanian. Karena produksi penduduk miskin relatif pada produk-produk tradisional sepertikerajinan tangan dan industri kecil disamping pertanian.Pengemangan produk'-produk ini perlu disesuaikan dengan kebutuhan pasar sehingga, produk tersebut mampu menciptakàn pasamya sendiri: Hambatan 
yang dihadapi dalam peningkatan volume penjualan barang-barang yang diproduksi oleh kaum miskin adalah, luas pasar yang dihadapinya. Produksi kerajinan dan industrikecil, kurang memiliki nilai tambah bagitenagakerjadi pedesaan dimana sentrasentra industri, banyak dijumpai. Jika kita berpikir menggunakan hukum Say, bahwa produksi itu akan menciptakan pasamya sendiri, maka kebijaksanaan dibidang produksi industri kecil dan kerajinan hendaknya diarahkan kepada kebutuhan pasar yang lebih luas yaitu bagi masyarakat desa itu sendiri dan kota. Bantuan yang diberikan kepada sektor ini tentu terkait dengan keuangan teknologi danmanajemen yang mampu memperbaiki dan membuat produk mereka menjadi dibutuhkan.

Pendekatan ketiga yang perlu dipertimbangkan pula adalah bagaimana meningkatkan harga jasa yang mereka tawarkan. Ùrbanisasi prematur ỳang menyebabkan tenaga kerja pedesaan tidak dapat - dipindahkan secara ekonomis ke sektor industri pengolahan menyebabkan terjadinya proses perpindahan ke sektor tersier yang prematurpula. Akibatnyaharga jasa yang ditawarkan dișektor ini menjadi rendah karena tidak didukung oleh kualitas tenaga kerja yang diharapkan.

Pendeketan-pendekatan tersebut hanya mungkin berhasil jika didukung oleh strategi pembangunan yang tepat. Pilihanpilihan yang mungkin adalah:

1. Strategi yang mengandalkan pertumbuhan yang berorientasi pada

- sektor bidang industri pengollahan yang bersifat padat karya.

2. Strategi industrilisasi yang dipelopori oleh pertanian.

Sangat sulituntukmelakukan pilihan secara tegas mana dari strategi yang dikemukakan Adelman tersebut yang paling baik bagi Indonesia dalam PJP II khususnya dalam pelita ke VI ini, sebab setiap pilihan mengandung konsekuensi yang cukup berat yaitu perlunya campur tangan pemerintah dalam bentuk kebijaksanaan harga baik komoditi perdagangan maupun barang-barang manufaktur hasil industri padat karya. peningkatan produktivitas petani melalui peningkatan dukungan pembangunan jalan, irigasi, teknologi dsb. Tetapi nampaknya kedua strategi tersebut dapat dipertimbangkan karena memungkinkan tumbuhnya perekonomian yang tidak menciptakan konglomerasi elit yang kontradiktif dengan program pemerataan seperti yang telah dialami selama PJP I.

Bentuk-bentuk bantuan yang diperlukan jika kedua strategi tersebut dipertimbangkan antara lain:

1. kredit perbankan dengan syarat-syarat yang lebih bisa dijangkau oleh unit-unit ekonomi berskala menengah. Bantuan ini sangat diperdukan karena sektorsektor yang paling padat karya dalam perekonomian adalah pertanian, industri kecil dan kerajinan.

2. péningkatan program pendidikan sehingga rintangan kesempatan kerja yang diakibatkan rendahnya tingkat ' pendidikan penduduk angkatan kerja dapat diperkecil. Dengan demikian mobilitas tenagá kerja tidak dalam keadaan prematur.

3. investasi modal kemanusiaan, Bantuan investasi dalam peningkatan gizi dan kesehatan akan memberikan efek langsung pada: kaum, miskin dan sekaligus dapat meningkatkan produktivitas kerja mereka'.

4. investasi pada_sumber-sumber daya 
pelengkap. Bentuk bantuan dalam hal ini antara lain peningkatan dalam investasi irigasi, pembuangan air dan pupuk.

\section{Program IDT}

Upaya penanggulangan kemiskinan melalui program IDT telah memberikan harapan baru bagi penduduk miskin di pedesaan. Program ini merupakan langkah strategis dalam upaya mewujudkan pemerataan dan keadilan, sosial melalui strategi kebijaksanaan ekonomi yang secara umum diwadahi oleh pembangunan ekonomi yang terdesentralisasi, menekankan pembangunan daerah dan pedesaan, serta prioritas sektor ekonomi rakyat (Mubyarto, 1994): Orientasi pengentasari kemiskinan melalui model ini diharapkan memberikan efeklangsung dan tidak bersifat "trickle down" karena bantuan bèrupa dana bersifat langsung pada desa yang menjadi sasaran. Program ini sangat relevan dengan pilihan strategi kedua Adelman yaitu industrialisasi yang dimotori pertanian. Pembangunan model desa IDT akan meningkatkan produktivitas disektor perekonomian subsisten.

Keadaan yang harus dihindari sebagai implikasi destruktif dari program ini adalah, masyarakat desa tidak menjadi dinamis melainkan menjadi masyarakat yang selalu "meminta": Oleh sebab itu bantuan dana yang diberikan kepada setiap Desa Tertinggal, haruslah lepas dari persoalan politik dan benar-benar tersalur pada kebutuhan seperti pembangunan prasarana, . program ketrampilan, penerangan listrik dsb, yang bersifat mendukung kesempatan penduduk miskin untuk meningkatkan produktivitasnya dan mampu memanfaatkan peluang-peluang ekonomi pedesaan yang mulai terbuka.

\section{Penutup}

Berdasarkan uraian dimuka mengenai pendekatan dan strategi penanggulangan kemiskinan dapat disimpulkan bahwa pilihan pendekatan dan strategi dalam pelaksanaan pembangunan ekonomi terutama pada pelita VI ini, perlu mempertimbangkan strategi yang berorientasi pada kekuatan pertanian dan industri manufaktur yang padat karya. Konsekuensi dari pelaksanaan strategi ini bantuan yang diberikan haruslah dalam konteks pengembangan faktor-faktor penentu produktivitas kelompok miskindan kebijaksanaan-kebijaksanaan yang bisa. meningkatkan nilai milik mereka, pasar bagi produk yang dihasilkan dan peningkatan upah atas jasa yang diberikan oleh kelompok miskin.

\section{Referensi}

John P.Lewis dan Veleriana Kállab (Ed)(1987), tulisan Irma Adelman (1987), Cara Pendekatan Kepada . Kebijakan Pembangunan yang Terpusät pada Kemiskinan, UIP.

Nurimansyah Hasibuan (1994), Distribusi Pendapatan dan Pertumbuhan Ekonomi, pada Seminar Nasional Fakultas EkonomiUII-ICMI, 25-26Maret, 1994.

Mubyarto (1994), Dari Program Stabilisasi Sampai Kebijaksanaan Pembangunan Berkelanjutan, pada Seminar Nasional. Fakultas Ekonomi UII-ICMI, 25-26 Maret, 1994. 